\title{
Working towards an integrated land contamination management framework for
}

\section{Nigeria}

Kabari Sam, Frédéric Coulon, George Prpich*

School of Water, Energy, and Environment, Cranfield University, College road, Cranfield, MK43

0AL, UK

*Corresponding author

Email: g.prpich@,cranfield.ac.uk

Tel: +441234750111 
ABSTRACT: Over the past five decades Nigeria has developed a number of contaminated land legislations to address the damage caused primarily by oil and gas exploitation activities. Within these legislations exist elements of risk assessment and risk-based corrective action. Despite this progress, we argue that contaminated land management approaches in Nigeria need further development to be able to integrate new scientific information, and to address environmental, economic, and social values. By comparison, advanced contaminated land regimes in the United Kingdom (UK), the Netherlands, Australia, New Zealand and the United States of America (USA) apply a number of integrative approaches (e.g. sustainability appraisal, liability regime, funding mechanisms, technology demonstration) that enable them to meet the environmental, economic, and social needs of their populations. In comparison, Nigerian governance lacks many of these mechanisms and management of contaminated land is ad hoc. In this paper we propose an integrated risk assessment framework for Nigeria that incorporates the principles of sustainability and stakeholder engagement into the decision-making processes for contaminated land risk assessment and risk management. The integrated approach relies on transparency to promote acceptance and build trust in institutions, and uses stakeholder engagement to address data deficiencies. We conclude this paper with a roadmap for how Nigeria might implement such an integrative approach into their existing contaminated land regulatory system, as well as identify a series of policy priorities that should be addressed.

Keywords: contaminated land, integrated framework, Niger Delta, risk assessment, sustainability appraisal 


\section{Introduction}

Over the last 50 years the growth of the Nigerian oil and gas exploitation industry has resulted in significant soil and water contamination issues, particularly in the Niger Delta region. Though policies and regulatory actions to protect the environment have been implemented in Nigeria to prevent deliberate pollution, and more recently to address pollution prevention at source (Ajayi and Ikporukpo, 2005; Ajai, 2010; Fentiman and Zabbey, 2015), deficiencies remain. Most notably, there is a need for a better integration and implementation of an environmental management strategy that reflects scientific and societal expectations (UNEP, 2011; Ambituuni, et al., 2014; Rim-rukeh, 2015), which both are viewed as necessary to manage land contamination (Idemudia and Ite, 2006; Eneh, 2011; Enuoh and Eneh, 2015).

Soil protection and management have been featured in Nigerian policy discussions since the late 1970s, for example see the Petroleum Act 1969 (FGN, 1969). More recently, this topic has become a priority concern for regulators and the public who regard the role of soil as a resource, independent of the functions that it carries out (Sojinu et al., 2010; UNEP, 2011; Adekola et al., 2015; Haslmayr et al., 2016) . This perspective is shared internationally (Swartjes et al., 2012; Artmann, 2016), and can explain the motivation for soil protection in other sectors including among others soil contamination (Baveye and Laba, 2016; Cachada et al., 2016), construction (Liu et al., 2015), and agriculture and amenity value (Stupak, 2016).

Frameworks for pollution prevention and risk-based management of contaminated lands are well established in North America and Europe. In the UK, risk-based approaches to land contamination management have resulted in a number of lessons that can be shared globally, in particular, the development of innovative cost effective approaches to land contamination management (Nathanail et al., 2013). Arguably, Nigeria could benefit from these experiences by adapting best practices now 
established in the UK. By leveraging existing knowledge and know-how, Nigeria might expect a decrease in both the cost and timeline for similar policy and regulatory development; however, changes must integrate with current initiatives. Management elements that should be considered in a comprehensive risk and sustainability assessment system include:

1. risk management decision making;

2. verification of remediation outcomes;

3. systems for record keeping and preservation and integration of contamination issues into land use planning, along with procedures for ensuring effective health and safety considerations during remediation projects; and

4. effective evaluation of costs versus benefits and overall sustainability, both for remediation and in the broader brownfields regeneration context.

In this study we discuss the challenges and opportunities for change in the current land contamination management regime in Nigeria, and suggest a way forward to establish an integrated risk assessment framework. Finally, we present a road map for the integration of environmental, economic and social values into a sustainable land contamination management plan for Nigeria.

\section{What is an integrated risk assessment framework?}

Risk assessment is a systematic approach to identify, evaluate, manage and communicate the likelihood of occurrence and consequences of harm resulting from land contamination (Defra, 2011; Prpich et al., 2015). Risk assessment is used to support decisions by providing a structured means to gather and organise evidence in support of rational and objective arguments. Risk assessment can be used to determine levels of harm, to prioritise issues, or to inform policy, and comprises a series of logical steps: identification, definition of scope, development of a conceptual model, assessment, 
characterisation, management, communication, that enable the assessment of any environmental activity (Defra, 2011). A significant step in the risk assessment process is the development of the conceptual site model (CSM), which is used to establish the links between source-pathway-receptors (Simon et al., 2016; Thomsen et al., 2016). Within the risk assessment framework, social, environment, and economic values are often considered to provide a holistic perspective.

The same principles are applied to risk assessment for land contamination (Briggs, 2008) and specific measures might include e.g. assessment of exposure and effects and impacts on local populations, identification of contaminant fate and transport and pollutant linkages, assessment of effects on multiple species/target organisms, toxicological endpoint identification, and sociotechnical assessment (Suter et al., 2003). To assess these components as a whole requires an integrated risk assessment framework, which is a risk-based framework that takes into account holistic factors such as social values, environmental and economic concerns, and sustainability, when making an estimation of risk (Suter et al., 2003). The inclusion of environmental, economic, societal values, as well as public concerns, augment the conventional technical analysis associated with risk assessment to provide a broader perspective that has been shown to improve acceptance and reliability of risk assessment outputs (Péry et al., 2013; Wilks et al., 2015). In addition, integrated risk assessments provide greater opportunity for engagement between risk assessors, decision makers, regulators, experts, operators and the public, because of the multiple information inputs (Figure 1).

\subsection{Stakeholder engagement}

Stakeholder engagement is the process of informing, consulting, involving, collaborating with, and empowering affected people involved in a decision making or policy-forming process (Rowe and Frewer, 2005; Cundy et al., 2013; Ramirez-Andreotta et al., 2014). In practice, stakeholder engagement integrates the views of different stakeholder groups, e.g. experts, public, regulators and 
operators, to arrive at a consensus decision (Cundy et al., 2013). Stakeholder engagement is a fundamental aspect of any integrated risk framework and is used to inform, consult, create dialogue, and empower interested parties to participate in the decision-making process (Reed, 2008; Benson et al., 2016). Evidence suggests that through involvement, stakeholders will enhance the quality of decision-making via introduction of variable information inputs (Garmendia and Stagl, 2010; Cundy et al., 2013; Sardinha et al., 2013). This is achieved by accessing, sampling, and integrating diverse stakeholder perspectives (including experts and non-experts) through an inclusive participatory process that facilitates new idea generation, while seeking to develop common understanding of shared perspectives (Sardinha et al., 2013). Stakeholder engagement can also be used to identify gaps in knowledge or reveal risk perceptions (Reed, 2008), and is often used to build trust and promote transparency, particularly for complex issues (Péry et al., 2013; Prpich et al., 2015).

However, the quality of outputs derived from stakeholder engagement processes will depend on the nature and relevance of the approach (Chess and Purcell, 1999). Communication must be meaningful and accessible, e.g. using common language that is understandable to all stakeholders, and culturally appropriate (Cundy et al., 2013), and therefore must be context specific (IFC, 2007). In the EU and US technology (e.g. emails, text messaging, online surveys, and other forms of social media) are often used to inform stakeholder groups about the engagement process and aims, and the venue location while also supporting facilitation of meetings and seminars, and question and answer sessions (Smith and Gallicano, 2015). In regions where these types of technologies are not available, these approaches could be counterproductive to the engagement process (Chess and Purcell, 1999). For example, stakeholder engagement processes in South Africa and Botswana accommodate for cultural differences in communication, advocating for the use of direct and physical contact with stakeholders in these regions (Department of Environmental Affairs and Tourism, 2002; Department of Water Affairs, 2012; Obasi and Lekorwe, 2014). In Nigeria, stakeholder engagement processes 
should involve a degree of physical contact, persuasion, and negotiation (Lawrence, 2002; Idemudia, 2014; Aluko et al., 2015) and if these techniques are not integrated into the process it might make stakeholders reluctant to participate in the policy process, possibly leading to feelings of exclusion or lack of trust, (Boele et al., 2001; Okoh, 2007).

\subsection{Sustainable contaminated land management}

Sustainability is defined as the aggregate of environment, social, and economic assessment. One of the first land contamination assessments to consider social and economic benefits was the Lower Swansea Valley Regeneration assessment in the UK (Bardos et al., 2016). Sustainability has since become the basis for contaminated land management in the UK and these practices have been shared with several European partners through the establishment of technical networking projects (e.g. CARACAS and CLARINET) (CARACAS, 1998; Vegter et al., 2002; Döberl et al., 2013). Specifically in the EU, the Concerted Action on Risk Assessment for Contaminated Sites in the European Union (CARACAS) created a knowledge sharing platform about contaminated land risk assessment for academics and experts (CARACAS, 1998), while the Contaminated Land Rehabilitation Network for Environmental Technologies (CLARINET) provided an interdisciplinary knowledge exchange network for the sustainable management of contaminated land management. The contaminated land applications in real environments (CL:AIRE) is another example of a network platform used to communicate information about contaminated land research, technology, and demonstrations worldwide (CL:AIRE, 2015; Bardos et al., 2016). Additional information exchanges include NICOLE ( $\underline{\text { www.nicole.org) }}$ ) and COMMON FORUM (www.commonforum.eu) Work is also underway to develop a sustainable remediation network in China via collaboration between the UK Sustainable Remediation Forum (SuRF-UK) and its Chinese equivalent. The aim of this partnership is to support the rapid progression of a sustainability debate about contaminated land 
in China, and to facilitate the development of guidance and training (Coulon et al., 2016). More generally, consensus is building that sustainable land management should be incorporated into an ISO standard (Bardos et al., 2016). Contextually, Nigeria might benefit from synergistic relationships with countries owning experience in sustainable land contamination management, for example, a collaboration with the SuRF-UK network could progress the sustainability debate in Nigeria, promote knowledge sharing, and support capacity building.

International consensus suggests that sustainable remediation should provide a net benefit across a range of environmental, economic, and social concerns. The first framework for sustainable remediation (SuRF-UK) was published by the UK and serves as the basis for similar frameworks in other countries (SuRF-UK, 2010; Bardos et al., 2016). The scope of sustainability is fluid, but can be summarised across these three key elements (Table1).

Table 1: Examples of commonly used criteria (receptors and impacts) considered when conducting a sustainability assessment. Criteria are spread across the three key elements of sustainability (Bardos et al., 2011, 2016; Hou and Al-Tabbaa, 2014; Hou et al., 2014; Rosén et al., 2015).

\begin{tabular}{lll}
\hline \multicolumn{1}{c}{ Environment } & \multicolumn{1}{c}{ Economic } & \multicolumn{1}{c}{ Social } \\
\hline Soil & Income loss & Protection of human health \\
Fauna and flora & Economic burden & Safe working practice \\
Groundwater & Employment opportunity & Local air quality \\
Surface water & & Equity \\
Sediment & Cultural heritage \\
Biodiversity loss & Local participation \\
Resource conservation & Local acceptance \\
Ecosystem services & Impact on property \\
Minimising waste & Impact on livelihood \\
\hline
\end{tabular}




\section{What are the opportunities for integrated risk assessment in the present Nigerian land contamination management regulatory landscape?}

Nigerian legislation for land contamination management is stretched across ten distinct pieces of legislation that cover five key areas of management (Table 2). Though all of the legislations address the prevention of land contamination and the protection of human and environmental receptors, only one legislation specifically describes the management of contaminated land - the Environmental Guideline and Standards for Petroleum Industry in Nigeria (EGASPIN). Despite this legislation, land contamination remains an ongoing issue across the Niger Delta, in particular the prevention of new contamination (Pegg and Zabbey, 2013). Nigeria needs a comprehensive legislative framework that can provide a definition for contaminated land, identify planning controls, assign liability, organise a funding structure, and develop sustainability indicators (Könnet, 2014). There is also a need for mechanisms to identify and investigate actual volumes and causes of spills (Rim-rukeh, 2015), remediate contaminated sites (UNEP, 2011), protect human health, and promote access to contaminated land information (Sam et al., 2015). 
Table 2: Legislations that relate to land contamination management in Nigeria and an assessment of their effective management areas.

\begin{tabular}{|c|c|c|c|c|c|}
\hline Legislation & Prevention & $\begin{array}{l}\text { Protection of } \\
\text { human health } \\
\text { and the } \\
\text { environment }\end{array}$ & Management & $\begin{array}{l}\text { Access to } \\
\text { information }\end{array}$ & $\begin{array}{l}\text { Sustainability } \\
\text { appraisal }\end{array}$ \\
\hline The Petroleum Act 1969 & $\nabla$ & $\nabla$ & 凶 & 凶 & 凶 \\
\hline $\begin{array}{l}\text { Federal Environmental Protection Act } \\
1988\end{array}$ & $\nabla$ & $\nabla$ & 凶 & 凶 & 凶 \\
\hline Harmful Waste Act 1988 & $\nabla$ & $\nabla$ & 凶 & 凶 & 凶 \\
\hline National Policy on Environment 1989 & $\nabla$ & $\nabla$ & 凶 & 凶 & 凶 \\
\hline Oil Pollution Act 1990 & $\nabla$ & $\nabla$ & 凶 & 凶 & 凶 \\
\hline $\begin{array}{l}\text { National Environmental Protection } \\
\text { (Abatement in Industries Generating } \\
\text { Wastes) Regulation } 1991\end{array}$ & $\nabla$ & $\nabla$ & 凶 & 凶 & $凶$ \\
\hline $\begin{array}{l}\text { National Environmental Protection } \\
\text { (Effluent limitation) Regulation } 1991\end{array}$ & $\nabla$ & $\nabla$ & 凶 & 凶 & 凶 \\
\hline Environmental Impact Assessment 1992 & $\nabla$ & $\nabla$ & 凶 & 凶 & 凶 \\
\hline $\begin{array}{l}\text { Constitution of the Federal Republic of } \\
\text { Nigeria } 1999\end{array}$ & $\nabla$ & $\nabla$ & 凶 & 凶 & 凶 \\
\hline $\begin{array}{l}\text { Environmental Guidelines and } \\
\text { Standards for Petroleum Industry in } \\
\text { Nigeria (EGASPIN) } 2002\end{array}$ & $\nabla$ & $\nabla$ & $\nabla$ & $凶$ & $凶$ \\
\hline
\end{tabular}

*Green - elements covered by the current land contamination regulations in Nigeria

Red - elements that are not currently covered by the current land contamination management regulations in Nigeria, but are needed

Nigeria's current contaminated land regulations lack a definition for contaminated land, funding mechanism for land remediation, a strategy for identifying and assigning liability, and an effective risk-based framework for land contamination management (Sam et al., 2015). In addition, the regulations lack the technical capability to identify, record, investigate, and validate contaminated sites, which limits the ability of regulators and operators to track pipeline vandalism and to identify oil spills promptly (Adelana and Adeosun, 2011; Rim-rukeh, 2015). Also lacking are a means for prioritising the clean-up of high-risk areas and mechanisms for the exchange of research between 
international and national regulatory agencies and experts (Egwu, 2012; Könnet, 2014; Rim-rukeh, 2015). Given these challenges, the need for a comprehensive legislative framework is obvious, however, implementation of such a framework will require significant policy changes (Yeeles and Akporiaye, 2016). We described and prioritise these challenges in Table 3.

Table 3: Overview of the opportunities for change within the key functions of the Nigerian land contamination framework

\begin{tabular}{|c|c|c|c|c|}
\hline Functions & $\begin{array}{l}\text { What is } \\
\text { currently in } \\
\text { place }\end{array}$ & $\begin{array}{c}\text { Level of } \\
\text { achievement }\end{array}$ & Opportunities for change & Priority $^{2}$ \\
\hline A legislative framework & $\begin{array}{l}\text { EGASPIN } \\
\quad 2002\end{array}$ & Partial & $\begin{array}{l}\text { This is in place but not appropriate. } \\
\text { Produce a new guidance that provides a } \\
\text { clear definition for contaminated land, } \\
\text { planning control liability regime, and } \\
\text { roles and responsibilities for agencies }\end{array}$ & High \\
\hline $\begin{array}{l}\text { Measures to prevent land } \\
\text { contamination }\end{array}$ & $\begin{array}{l}\text { Petroleum } \\
\text { Act } 1969\end{array}$ & Partial & $\begin{array}{l}\text { A clear inclusion of the precautionary } \\
\text { principle to use technology to detect and } \\
\text { monitor pipeline cracks and vandals }\end{array}$ & Medium \\
\hline $\begin{array}{l}\text { Access to contaminated land } \\
\text { information }\end{array}$ & Nil & Nil & $\begin{array}{l}\text { Produce a guidance to develop a } \\
\text { database for extent and status of } \\
\text { contaminated land in Nigeria }\end{array}$ & Low \\
\hline Funding & Nil & Nil & $\begin{array}{l}\text { Produce a funding mechanism for } \\
\text { contaminated land }\end{array}$ & High \\
\hline Sustainability appraisal & $\begin{array}{l}\text { EGASPIN } \\
\quad 2002\end{array}$ & Partial & $\begin{array}{l}\text { A clear framework for integrating } \\
\text { sustainability indicators in the } \\
\text { contaminated land decision making }\end{array}$ & Medium \\
\hline $\begin{array}{l}\text { Protection of human health } \\
\text { and environment from the } \\
\text { impacts of contaminated } \\
\text { land }\end{array}$ & $\begin{array}{l}\text { EGASPIN } \\
\quad 2002\end{array}$ & Partial & $\begin{array}{l}\text { Produce nationally consistent methods } \\
\text { for deriving human health and ecological } \\
\text { soil screening levels for Nigeria }\end{array}$ & Medium \\
\hline $\begin{array}{l}\text { Mechanisms to help } \\
\text { identify, investigate, } \\
\text { manage and remediate } \\
\text { contaminated land }\end{array}$ & $\begin{array}{l}\text { EGASPIN } \\
2002\end{array}$ & Partial & $\begin{array}{l}\text { Consider a new guidance; review and } \\
\text { revise existing guidance }\end{array}$ & Medium \\
\hline
\end{tabular}

${ }^{\mathrm{a}} \mathrm{We}$ define a high priority as a necessary starting point for an inclusive integrated approach, while a low priority is one that is not considered a necessary starting point.

Of the priorities that we identified, we believe that the highest priority should be the review and revision of the current land contamination management framework. Fundamental to this revision is 
the development of an appropriate definition for contaminated land that would provide the basis for risk quantification (UNEP, 2011). Development of the definition could borrow from countries with vast experience in land contamination management, e.g. UK and US. A working definition could help to mitigate disputes between regulators and operators that arise due to discretional definitions often provided by the regulator (DPR, 2002). Though the federal agency or government should assume the lead in the development and implementation of a statutory definition for contaminated land, the process should be inclusive of levels of government. A similar approach is practiced in the US (a federal state) where the United States Environment Protection Agency (USEPA) ensures the inclusion of regional and state environmental management agencies in land contamination decision making processes.

As a second priority, a funding mechanism for land contamination management should be institutionalised. The United Nations Environment Programme (UNEP) report on Ogoniland, indicated that clean-up will require an investment of over 1 billion USD (UNEP, 2011) and because funding constraints limit the effectiveness of clean-ups (Könnet, 2014), the lack of a funding mechanism is concerning. Examples of funding mechanisms include diversion of a percentage of the income on the sales of petroleum products to a clean-up fund or strict enforcement of the polluter pays principle (Sam et al., 2015). With a revised regulatory framework and adequate funding it is expected that the additional medium- and low-priority actions could be addressed in reasonable timeframe.

It is clear that the strategy to manage land contamination in Nigeria is at an early stage of development (i.e. Nigeria developed a specific land contamination regulation in 2002) (DPR, 2002; Ajayi and Ikporukpo, 2005). Changes to this strategy are necessary to achieve the level of comprehensive policy that is envisioned. We believe that at its core, a land contamination management system should comprise an integrated approach that combines risk-based principles, 
stakeholder engagement, and sustainability assessment to provide a comprehensive land contamination policy. In the following section, we describe such an approach, and discuss how it could be used to promote better land contamination management in Nigeria.

\section{An integrated risk assessment framework for Nigeria}

Integrated risk assessment frameworks have been developed previously, e.g. for organophosphorus pesticides (Vermeire et al., 2003), ultraviolet radiation effects on amphibians, coral, humans, and oceanic primary productivity (Hansen et al., 2003), persistent organic pollutants in humans and wildlife (Ross and Birnbaum, 2003), and for assessment of tributyltin and triphenyltin compounds (Sekizawa et al., 2003). These examples demonstrate how an integrated risk assessment framework can redefine a traditional risk assessment process in terms of better inputs (more inclusive), streamline the process, include stakeholders, and share information (Suter et al., 2005).

Our proposed framework will seek to achieve two aims:

(i) integrate environmental and socio-economic inputs (i.e. sustainability) into the risk assessment, and risk management processes;

(ii) provide a trusted and transparent approach to risk analysis that meets stakeholder expectations and promotes involvement (Wilks et al., 2015).

The proposed framework was designed to address issues about data availability, and does this via an iterative stakeholder engagement process that connects all elements of the risk analysis process (i.e. risk assessment, risk communication, and risk management) and also includes stakeholder values. Stakeholders are urged to contribute and review findings at each step in the process with the level of interaction depending on the nature and complexity of the assessment. 
The integrated assessment framework consists of five steps:

1. Problem formulation: the objective and scope of the risk assessment are defined, a conceptual site model is developed to identify all Source-Pathway-Receptor linkages, all relevant stakeholders are involved at this stage, and the nature and extent of stakeholders' future involvement is defined.

2. Hazard identification: hazards are identified, their source is identified, and the properties of both hazards and sources are defined and classified as posing a risk or no risk.

3. Exposure assessment: the likelihood of a receptor being exposed to a hazard is defined, which takes into account the magnitude, and duration of the exposure, as well as who and what are exposed, for how long, and how often.

4. Risk estimation: risk is estimated by multiplying the likelihood of probability and the extent of the harm.

5. Risk characterisation: a quantitative or semi-quantitative estimate of risk is determined and this includes an estimate of uncertainty, and a statement of significance, i.e. is a risk something to worry about?

By integrating environmental, economic and social values into the generic assessment of land contamination in Nigeria (Figure 1), the framework considers the principle of sustainability. 


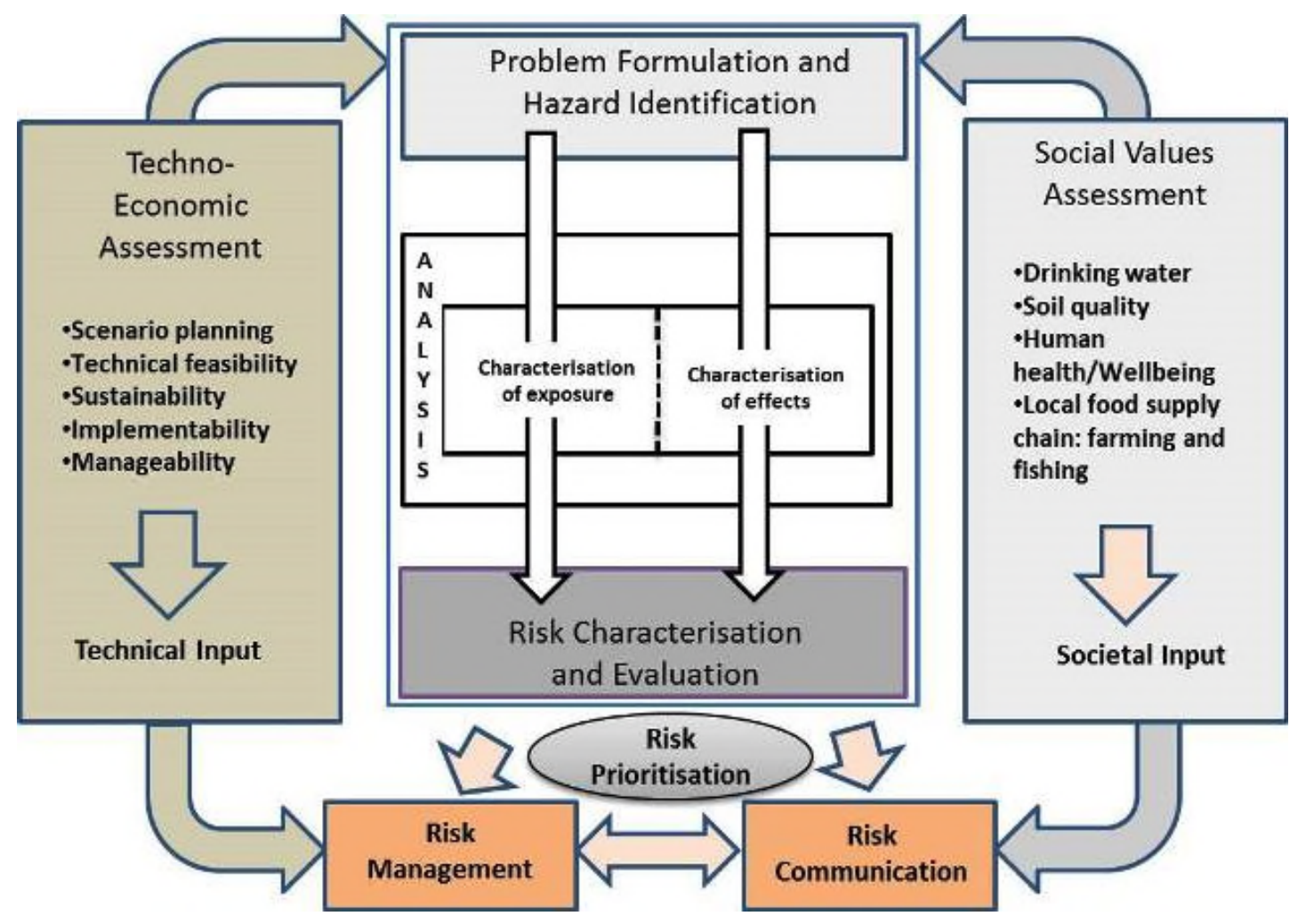

Figure 1: Integrated framework for sustainable land contamination risk assessment in Nigeria.

A central feature of any integrated risk assessment framework is the ability to combine independent sources of relevant information (Wilks et al., 2015). In the proposed framework, we envision this being provided via stakeholder engagement whereby input from relevant stakeholder groups is used to contribute to the risk assessment and management, and decision making processes.

An added value of the integrated risk assessment framework is that the engagement process provides opportunity for consideration of all impacts of land contamination that are normally kept separate during traditional risk assessment (Briggs, 2008; Suter et al., 2005). For example, local communities can better characterise different pathways through which they might be exposed because of their local knowledge (Pollard et al., 2004; Reed, 2008; Bardos et al., 2016). This type of inclusivity enables stakeholders to also assist with the screening of environmental impacts and to integrate socio-political and economic factors that might influence environmental decision-making (Pollard et al., 2004). 
Using this framework, sustainable decisions about land contamination management can be arrived at because it provides a mechanism for the coordinated exchange of information, the sharing of assumptions and data between stakeholders, and the inclusion of local knowledge. This provision is intended to garner wider consultation and consideration, which should translate into an improved and efficient assessment process (Garmendia and Stagl, 2010; Sardinha et al., 2013; Bardos et al., 2016). As a consequence of this framework, it might be expected that Nigeria seeks to develop a more structured and informative risk assessment that would be relevant to sustainable contaminated land management (i.e. inclusion of the environmental and socio-economic effects). From the public's perspective, this framework could be expected to build trust between stakeholders and establish confidence in the process of contaminated land management through improved transparency. In the following sections we provide further detail about the key aspects of the framework.

The Nigerian Government could deploy this framework at all levels of government (e.g. national site prioritisation, regional management, or local site assessment) to address stakeholder concerns about participation in the land contamination management process (Rim-rukeh, 2015; UNEP, 2011). The framework could be used to facilitate workshops (Idemudia, 2014b), or guide site investigations that require inclusion of different stakeholder groups (Rim-rukeh, 2015), and also to determine remediation action (UNEP, 2011). By doing so, the outcome of the engagement process will reflect stakeholder expectations and might reduce the conflict that exists between land contamination stakeholders (Umukoro, 2012; UNEP, 2011). 


\subsection{Facilitating collaboration and interactions between stakeholders}

The framework provides a structured process for all stakeholder groups to engage at the beginning (problem formulation stage) through to the end of the assessment process. This ensures that relevant and wider issues affecting all stakeholder groups can be integrated into the decision process, thereby fostering mutual understanding and closer collaboration (Garmendia and Stagl, 2010; Bardos et al., 2016). As such, integrated risk assessment frameworks can bridge the gaps between stakeholder groups in the decision making process by providing them a role in the engagement process, which in turn engenders transparency in the decision process (Reed, 2008; Sardinha et al., 2013).

\subsection{Fostering expectation from all stakeholders}

Early and continual engagement is expected to foster group interactions (between risk-assessors and stakeholder groups) (Reed, 2008) through workshops (Idemudia, 2014a), and by enabling all actors to communicate expectations and risks clearly, and at the local level, better understanding of the process can be expected among stakeholders (Pollard et al., 2004). However, effective management of expectations requires that all stakeholder groups participate in this process, because this will ensure that stakeholder views are shared and that opportunities to clarify misunderstandings (e.g. values, language, culture) are made available.

\subsection{Resolving capacity issues among stakeholders}

Clean-up of contaminated land in the Niger Delta has been limited by the availability of technical capacity to conduct risk assessments and carry out management processes, and this has been linked to inadequate funding (UNEP, 2011). Accessing knowledge exchange and data sharing using the integrated framework can overcome capacity issues overcome without the need for additional funding. It could be expected that dedicated training programmes to implement the integrated risk 
assessment framework might also be used to enhance understanding of risk assessment and management amongst stakeholders. By increasing the communal knowledge about the complexity of risk, we should observe an improvement in contaminated land management in the region.

\subsection{Data harmonisation, sharing and use}

Risk assessment quality is dependent on the input data used to populate it (Wilks et al., 2015). Using low quality data (e.g. incomplete, inaccurate) introduces uncertainty to the assessment that could be transferred or amplified elsewhere in the process. Subjective judgement can be used to supplement data and this approach benefits from many different perspectives. Based on this concept, the framework relies on stakeholder engagement to supplement existing knowledge and to verify data about land contamination decisions. Inputs from the local population might be used to identify exposure routes that might not be obvious to experts, for example, the uptake of contaminants via the soil by a local plant that is used for traditional medicine. Input from locals can help to characterise, define, and prioritise risks based on actual or observed impacts that might also have otherwise been overlooked. Relevant information that is generated can then be harmonised through the integrated approach via assessment according to the different elements of sustainability.

\subsection{Considering socio-economic factors}

Most conventional risk assessments provide outputs in terms of technical surrogates (e.g. a margin of safety) that might challenge stakeholders' comprehension (EC, 2013). By expressing risk assessment outputs in terms of socio-economic values, outputs become more meaningful to the individual and this should improve both engagement and understanding amongst different stakeholder groups (Wilks et al., 2015). Improved understanding at the local level could lead to better risk management of day-to-day concerns (e.g. consumption of contaminated drinking water, fishing in contaminated waters) thus preventing secondary and tertiary impacts of land 
contamination. In addition, social values might include a multitude of issues, e.g. ecosystem services, non-quantifiable natural resources, cultural and economic resources (Pegg and Zabbey, 2013). It has been established that the inclusion of social values into a risk assessment process facilitates the achievement of societal expectations (Munns et al., 2003; Suter et al., 2003), and might lead to better risk communication and management (Burger, 2008).

\section{Defining and incorporating sustainability into land contamination management decisions in Nigeria}

The current contaminated land policy in Nigeria does not account for sustainability in a meaningful manner, nor does it take into account the socio-economic aspects of land contamination management (WCED, 1987; Orubu et al., 2004; UNEP, 2011). We believe there is scope for joint actions between relevant stakeholders to address these gaps and we argue that an emphasis should be placed on the development of risk assessment, remediation, human health impact assessment, and regulatory frameworks. Ideally, these aspects would be included under a single, overarching framework, but to do so will require a new and comprehensive policy.

We propose a pathway to integrate the principles of sustainability into the land contamination management decision-making process (Figure 2). The pathway comprises six steps that are intended to help decision makers at all levels to consistently structure and think through this process. The steps are as follows:

1. Identify sustainability indicators used to assess sustainability compliance. These indicators might include (but are not limited to) drinking water quality, fishing, human health, soil quality, groundwater condition, local food supply chain and income. 
2. Organise indicators according to the main pillars of sustainability, i.e. environment, economic and social. If necessary, for each family of indicators (e.g. social), identify different sub-indicators (e.g. human health).

3. Determine each indicator's impact on the decision process using stakeholder input, e.g. regulators, experts, operators, and the public (Krajnc and Glavic, 2005). Where necessary, identify sub-indicators. For example, drinking water is considered the most sensitive receptor to contamination in the Niger Delta suggesting that drinking water should receive a high impact rating (Nwidu et al., 2008).

4. Assign weights to the indicators based on local context using expert judgement and stakeholder engagement (Kiker et al., 2005; Linkov et al., 2005; Burger, 2008; Mayes et al., 2009).

5. Rank indicator importance for the Nigerian context based on the assigned weights of impact, giving priority to indicators that own higher weights.

6. Apply the weights to the land contamination management decision-making process for Nigeria. 


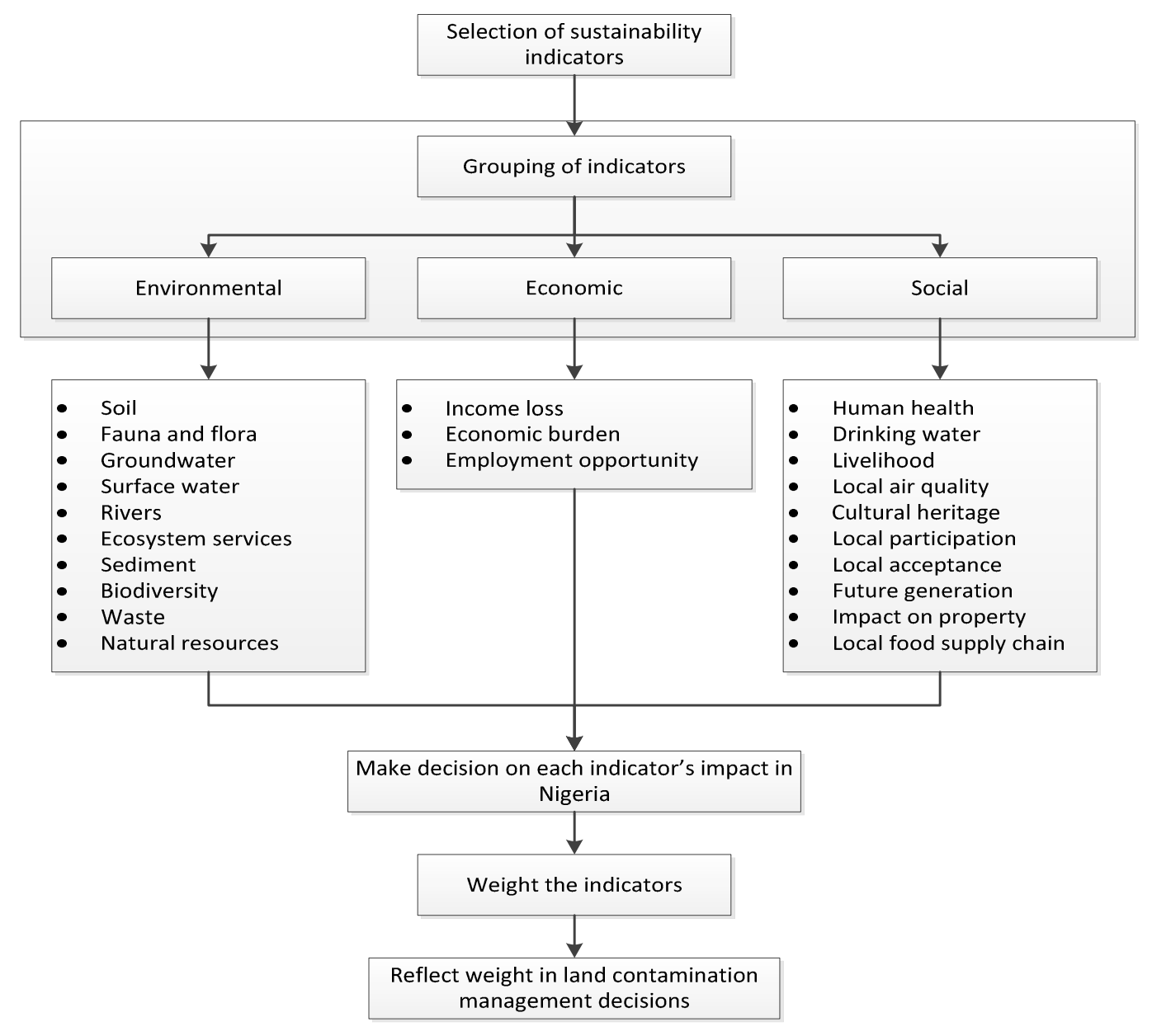

Figure 2: Proposed procedure for integrating sustainability in contaminated land management in Nigeria

\section{Implementation of the integrated risk assessment framework}

Time, resource, and technical capacity will be needed to implement an integrated risk assessment framework. In this section we identify a number of mechanisms that can be used to promote implementation, and these include building awareness, training, regulatory development, and gradual replacement of the existing contaminated land framework. 


\subsection{Create mechanism for awareness and stakeholder training}

Nigeria needs to raise awareness about the benefits of sustainable contaminated land management. This can be achieved through stakeholder engagement, seminars, and consultations at the local, state, and federal levels. The aim is to provide an opportunity for all stakeholders to have access to the framework and to contribute to the implementation process. This can be achieved via seminars, conferences and workshops, involving operators in the oil exploration industry, local communities impacted by oil spills, experts, and regulators of contaminated land. This type of engagement should also involve academics and scientists from different disciplines to explore other opportunities such as knowledge sharing presented by the framework. Effort should primarily focus on familiarising stakeholders with the concept, before shifting to integration into the existing regulatory regime.

Structured education and training programmes are required for all stakeholders to build capacity in the use of the framework. The multidisciplinary nature of the integrated risk assessment framework requires a dedicated and cross-functional training programme for risk assessors, local communities, regulators, and experts. Training programmes can improve levels of scientific knowledge among stakeholders and can be used to communicate understanding across institutional boundaries. Pragmatically, training might take the form of certification provided by professional bodies (e.g. Institute of Environmental Management \& Assessment (iema) in Nigeria) or workshops used to raise public awareness of the issues.

Case studies have been shown to provide convincing and pragmatic evidence to demonstrate how a framework like ours can advance the current practice (Vermeire et al., 2007; Wilks et al., 2015). We recommend that real life proof-of-concept case studies be used to validate the process and to demonstrate the cost-benefits offered. Where necessary, guidance should be developed to provide stakeholders the consistent means to define standards, expectations, and goals. 


\subsection{Multidisciplinary input}

Integrated assessments augment conventional scientific and technical risk assessment processes by using expertise from other disciplines. This type of participation can aid definition of, for example, spatial scenarios, and can be used to describe exposure of wider populations and protected areas. Increasing the number of stakeholders involved in the process does add to the complexity of the process, and this might lead to a difference of opinions about the nature of analysis. However, our process is intended to avoid disagreements by setting out the scope and level of involvement of stakeholders at the beginning of the framework (Wilks et al., 2015). Multidisciplinary input (e.g. chemists, agriculturalists, economists, hydrologists, toxicologists, ecologists, among others) will enhance the credibility of the process, expand the reach of the message, and should reduce inherent biases (Dreyer et al., 2010; Wilks et al., 2015).

\subsection{Replacement of existing framework with integrated risk assessment framework}

As familiarity and confidence in the framework grows, we would expect a gradual replacement of the original risk assessment approach with our proposed integrated framework. We might also expect that the inherent transparency associated with the proposed framework will build stakeholder trust, and thus promote further this gradual replacement. A regulatory guidance will finally be required to formalise the acceptance and incorporation of the framework into the land contamination management regime in Nigeria.

\subsection{Create knowledge exchange platforms}

The US, Netherland, Australia, New Zealand and the UK have made significant progress to incorporate sustainable development into land contamination management, and this has been done 
through knowledge exchange platforms such as the Sustainable Remediation Forum (SuRF) (SuRFUK, 2010; Bardos et al., 2011a, 2016). SuRF enables industry experts to exchange knowledge about sustainable remediation approaches, and this forum has advanced these concepts in the UK and European context (Hou, Al-Tabbaa and Guthrie, 2014). Nigeria would benefit from a similar platform, e.g. SuRF Nigeria, which would be used to introduce and facilitate the inclusion of sustainable ideas into land contamination management. Such a forum should be established at all levels of land contamination management governance in Nigeria including the federal, state and local councils levels.

\subsection{Funding}

The implementation of a land contamination management programme is capital intensive and a funding mechanism is needed to contribute to real on-the-ground actions. Currently no funding mechanism to support contaminated land risk assessment or remediation of identified sites exists (UNEP, 2011), and this lack of funding structure is likely responsible for the lack of publishable evidence regarding implementation of the 2011 United Nations recommendations (Könnet, 2014).

\subsection{Access to contaminated land information}

At a national level, Nigeria does not have a clear understanding of the extent of land contamination that requires assessment and remediation (UNEP, 2011). Data on estimates on the scale of land contamination is lacking, and this poses a considerable challenge to future clean-up. A central contaminated land database, developed in collaboration with local communities, is needed to help identify, monitor, and manage sites. Information contained within the database might include location, volume and type of contamination, scale of contamination, identity of receptors, proximity to receptors, date of spill, and where applicable actions taken to mitigate contamination. Such a database would provide the evidence necessary to enable the prioritisation of actions, national 
reporting on the effectiveness of land contamination policy (e.g. assessing changes in the number and severity of contaminated sites), and the improvement of policy development (MfE, 2006). Currently, neither regulators nor operators are mandated to make contaminated land information publicly available and therefore, a first step towards development of a database is a regulation that makes reporting about land contamination an obligation and accessible to other practitioners.

\section{Proposed roadmap for implementing the land contamination risk- based management framework for managing contaminated land in \\ Nigeria}

Implementation of an integrated risk assessment framework for land contamination in Nigeria will require concerted effort to generate agreements between stakeholders regarding the approaches used to incorporate the framework into regulatory practice. In the following sections we identify the short-, mid-, and long-term priorities that Nigerian government should endeavour to effect the proposed changes.

\subsection{Short-term priority (within a year)}

High priority within the shortest term includes:

- revise the current policy to include a definition for contaminated land and process for identifying a responsible person for land contamination;

- develop a funding mechanism to support land contamination management in Nigeria.

The rational here is that steps towards the management of land contamination should be based on a comprehensive legislation, and that implementation will require sufficient funding. We believe that 
these two elements should receive urgent attention. Following this, a multi-stakeholder working group to guide implementation should be developed. The working group should coordinate and harmonise implementation strategies, for example, structuring approaches and timelines on how the framework can be merged into the existing regulatory structure. Real-life case studies should be used to demonstrate proof of concept and framework usefulness. Finally, the working group should detail a pathway for the creation of professional contaminated land management groups (e.g. SuRF Nigeria).

\subsection{Mid-term priority $(2-3$ years $)$}

In the medium term, guidance should be provided on the:

- $\quad$ specific roles and responsibilities of different stakeholders;

- mechanisms for integration of sustainability indicators in the decision-making process;

- development of a national information centre/database about the scale and status of contaminated land;

- development of contextual standards for the protection of human and ecological health in the Niger Delta (e.g. soil screening values).

We recommend that efforts be made to harmonise land contamination risk assessment practices (e.g. identify acceptable methods to establish and assess source-pathway-receptor linkages) across government and that this should be facilitated by the regulator at all government levels. In addition, increased consultations between stakeholders should be encouraged to promote public awareness, and education should be provided to all stakeholder groups about policy development and the impacts this might have on operations. 


\subsection{Long-term priority (after 5 years)}

In the long-term, a comprehensive legislation that incorporates water and soil contamination management in Nigeria should be developed. Facilitated by the regulator responsible for the protection of human and environmental health, the new policy framework should clearly define what is contaminated land, and the roles of different regulatory agencies and of other stakeholder groups in sustainable land contamination management, as well as identify the need for planning controls, mechanisms for funding contaminated sites, and liability mechanisms. Plans should also be developed for training of personnel, provision of logistics, contaminated land clean-up, identifying and monitoring of spills, pipeline cracks and vandalism. Due to the extent of land contamination in the region, the development of such a framework is timely. Moreover, a framework that promotes stakeholders participation could be used as a reference for other countries in the region that face similar challenges related to oil exploitation (e.g. Ghana).

\section{Conclusion}

The challenge of managing land contamination is not a new one. It has been recognised by governments internationally for at least thirty years and is closely associated, technically and legislatively, with the issues of waste and hazardous waste disposal, the regeneration of derelict land, groundwater pollution and industrial site decommissioning. While there is some evidence that the policies in Nigeria have had some effect, there is still considerable scope for strengthening the implementation of environmental policies and developing integrated risk-based assessments for the management of land contamination. In order to increase effectiveness of the environmental regulations and to limit negative environmental and health impacts of rapid economic growth, the Nigeria authorities should consider the following: 
- Development of more consistent, transparent, and integrative environmental laws;

- Increased levels of public participation in the regulatory process that can be facilitated through the integrated risk-based approach proposed in this paper;

- Strengthen the capacities of environmental administrations in Nigeria and align their responsibilities with appropriate levels of funding;

- Recommend an overarching guidance structure and establish an independent information bureau like CL:AIRE;

- Develop an appropriate compliance assurance strategy through awareness raising, capacity building, and incentives for better environmental behaviour;

- Increase international collaboration with professional organisations such as SuRF-UK, for the management and sustainable development of land contamination to gain access to a shared experience.

In sum, this paper proposed an integrated risk assessment framework for the management of contaminated land in Nigeria. The framework stressed the inclusion of stakeholder engagement and social values into the decision process and shows that adoption of this framework might enhance institutional trust, promote equity of decision making, and improve risk reporting activities across the region. This paper contributes towards the advancement of sustainable land contamination management practice in Nigeria, and could serve as an exemplar for other oil producing countries in the region.

\section{Acknowledgements}

Niger Delta Development Commission in Nigeria through the Foreign Scholarship Program sponsored Kabari Sam. 


\section{Reference}

Adekola, O. et al. (2015) 'Inequality and ecosystem services: The value and social distribution of Niger Delta wetland services', Ecosystem Services, 12 Elsevier, pp. 42-54.

Adelana, S. and Adeosun, T. (2011) 'Environmental pollution and remediation: challenges and management of oil Spillage in the Nigerian coastal areas', American Journal of Scientific and Industrial Research, 2(6), pp. 834-845.

Ajai, O. (2010) 'Balancing of interests in environmental law in Nigeria', The balancing of interests in environmental law in Africa, , p. 379.

Ajayi, D.D. and Ikporukpo, C.O. (2005) 'An analysis of Nigeria's environmental vision 2010', Journal of Environmental Policy and Planning, 7(4), pp. 341-365.

Aluko, F. et al. (2015) 'Citizen' s Engagement Habit and Use o f ICT tools in Disaster Emergency Management: an account of flooding in Nigeria', International Journal of Advanced Studies in Computer Science and Engineering, 4(12), p. 2015.

Ambituuni, A. et al. (2014) 'Analysis of safety and environmental regulations for downstream petroleum industry operations in Nigeria: Problems and prospects', Environmental Development, 9(0), pp. 43-60.

Artmann, M. (2016) 'Urban gray vs. urban green vs. soil protection - Development of a systemic solution to soil sealing management on the example of Germany', Environmental Impact Assessment Review, 59 Elsevier Inc., pp. 27-42.

Bardos, P. et al. (2011) 'Applying sustainable development principles to contaminated land management using the SuRF?UK framework', Remediation Journal, 21(2) Wiley Online Library, pp. $77-100$.

Bardos, R.P. et al. (2016) 'The rationale for simple approaches for sustainability assessment and management in contaminated land practice', Science of The Total Environment, The Authors

Baveye, P.C. and Laba, M. (2016) 'Comment on "Potential of integrated field spectroscopy and spatial analysis for enhanced assessment of soil contamination: A prospective review" by Horta et al.', Geoderma, 271 Elsevier B.V., pp. 254-255.

Benson, D. et al. (2016) 'Evaluating social learning in England flood risk management: An “individual-community interaction” perspective', Environmental Science and Policy, 55 Elsevier Ltd, pp. 326-334.

Boele, R. et al. (2001) 'Shell, Nigeria and the Ogoni. A study in unsustainable development: II. Corporate social responsibility and "stakeholder management" versus a rights?based approach to sustainable development', Sustainable Development, 9(3) Wiley Online Library, pp. 121-135.

Briggs, D.J. (2008) 'A framework for integrated environmental health impact assessment of systemic risks', Environmental Health, 7(1), p. 61.

Burger, J. (2008) 'Environmental management: Integrating ecological evaluation, remediation, restoration, natural resource damage assessment and long-term stewardship on contaminated lands', Science of the Total Environment, 400(1-3), pp. 6-19.

Cachada, A. et al. (2016) 'Risk assessment of urban soils contamination: The particular case of polycyclic aromatic hydrocarbons', Science of The Total Environment, 551-552 Elsevier B.V., pp. 271-284. 
CARACAS (1998) Risk Assessment for Contaminated Sites in Europe. UK: European Commision.

Chess, C. and Purcell, K. (1999) 'Policy Analysis Public Participation and the Environment : Do We Know What Works?', Environmental science \& technology, 33(16), pp. 2685-2692.

CL:AIRE (2015) Sustainable Remediation Forum UK.

Coulon, F. et al. (2016) 'China's soil and groundwater management challenges: Lessons from the UK's experience and opportunities for China', Environment International, 91 Elsevier Ltd, pp. 196200.

Cundy, A.B. et al. (2013) 'Developing principles of sustainability and stakeholder engagement for "gentle" remediation approaches: The European context', Journal of Environmental Management, 129 Elsevier Ltd, pp. 283-291.

Defra (2011) Guidelines for Environmental Risk Assessment and Management: Green Leaves III. UK: Department for environment, food and rural affairs.

Department of Environmental Affairs and Tourism (2002) Stakeholder Engagement 3. South Africa. Department of Water Affairs (2012) Stakeholder Engagement Plan. South Africa.

Döberl, G. et al. (2013) 'Introducing a goal-oriented sustainability assessment method to support decision making in contaminated site management', Environmental Science \& Policy, 25(0), pp. 207-217.

DPR (2002) Environmental Guidelines and Standards for the Petroleum Industry in Nigeria. Lagos, Nigeria: Department of Petroleum Resources.

Dreyer, M. et al. (2010) 'Including social impact assessment in food safety governance', Food Control, 21(12) Elsevier Ltd, pp. 1620-1628.

EC (2013) 'Scientific Committee on Health and Environmental Risks SCHER Scientific Committee on Emerging and Newly Identified Health Risks SCENIHR Scientific Committee on Consumer Safety SCCS Toxicity and Assessment of Chemical Mixtures', (March), pp. 1-50.

Egwu, S. a. (2012) 'Oil Spill Control and Management', Petroleum Technology Development Journal (PTDF), 1(January), pp. 1-6.

Eneh, O.C. (2011) 'Managing Nigeria's environment: The unresolved issues', Journal of Environmental Science and Technology, 4(3), pp. 250-263.

Enuoh, R. and Eneh, S. (2015) 'Corporate Social Responsibility in the Niger Delta Region of Nigeria: In Who's Interest?’, Journal of Management and Sustainability, 5(3), pp. 74-84.

Fentiman, A. and Zabbey, N. (2015) 'The Extractive Industries and Society Environmental degradation and cultural erosion in Ogoniland: A case study of the oil spills in Bodo', The Extractive Industries and Society, 2 Elsevier Ltd., pp. 615-624.

FGN (1969) The Petroleum Act Nigeria, Lagos, Nigeria

Garmendia, E. and Stagl, S. (2010) 'Public participation for sustainability and social learning: Concepts and lessons from three case studies in Europe', Ecological Economics, 69(8) Elsevier B.V., pp. 1712-1722.

Hansen, L. et al. (2003) 'Integrated human and ecological risk assessment: A case study of ultraviolet radiation effects on amphibians, coral, humans, and oceanic primary productivity', Human and Ecological Risk Assessment, 9(1 SPEC. ISS.), pp. 359-377.

Hou, D. and Al-Tabbaa, A. (2014) 'Sustainability: A new imperative in contaminated land remediation', Environmental Science \& Policy, 39(0), pp. 25-34. 
Hou, D. et al. (2014) 'The adoption of sustainable remediation behaviour in the US and UK: A cross country comparison and determinant analysis', Science of The Total Environment, 490(0), pp. 905913.

Idemudia, U. (2014a) 'The Extractive Industries and Society Corporate-community engagement strategies in the Niger Delta: Some critical reflections ", Extractive Industries and Society, 1(2) Elsevier Ltd, pp. 154-162.

Idemudia, U. (2014b) 'Corporate-community engagement strategies in the Niger Delta: Some critical reflections', Extractive Industries and Society, 1(2) Elsevier Ltd, pp. 154-162.

Idemudia, U. and Ite, U. (2006) 'Demystifying the Niger Delta conflict: Towards an integrated explanation', Review of African Political Economy, 33(109), pp. 391-406.

IFC (2007) Stakeholder Engagement : A Good Practice Handbook for Companies doing Business in Emerging Markets.

Kiker, G. a et al. (2005) 'Application of multicriteria decision analysis in environmental decision making.', Integrated environmental assessment and management, 1(2), pp. 95-108.

Könnet, B.R. (2014) 'Inadequate Monitoring and Enforcement in the Nigerian Oil Industry: The Case of Shell and Ogoniland', Cornell International Law Journal, 11(2010), pp. 181-205.

Krajnc, D. and Glavic, P. (2005) 'A model for integrated assessment of sustainable development', Resources, Conservation and Recycling, 43(2), pp. 189-208.

Lawrence, A.T. (2002) 'The Drivers of Stakeholder Engagement', Journal of Corporate Citizenship, 2002(6), pp. 71-85.

Linkov, I. et al. (2005) 'Multi-criteria decision analysis: a framework for structuring remedial decisions at contaminated sites', in Comparative risk assessment and environmental decision making. Kluwer, Amsterdam: Springer, pp. 15-54.

Liu, T. et al. (2015) 'Construction land expansion and cultivated land protection in urbanizing China: Insights from national land surveys, 1996-2006’, Habitat International, 46 Elsevier Ltd, pp. $13-22$.

Mayes, W.M. et al. (2009) 'A national strategy for identification, prioritisation and management of pollution from abandoned non-coal mine sites in England and Wales. I. Methodology development and initial results', Science of the Total Environment, 407(21) Elsevier B.V., pp. 5435-5447.

MfE (2006) Working towards a comprehensive policy framework for managing contaminated land in New Zealand.

Munns, W.R. et al. (2003) 'Approaches for integrated risk assessment', Human and Ecological Risk Assessment, 9(1), pp. 267-272.

Nathanail, C.P. et al. (2013) International Processes for Identification and Remediation of Contaminated Land. Nottingham, UK: Land Quality Management Ltd.

Nwidu, L.L. et al. (2008) 'Assesment of the water quality and prevalence of water borne diseases in Amassoma, Niger Delta, Nigeria', African Journal of Biotechnology, 7(17), pp. 2993-2997.

Obasi, I.N. and Lekorwe, M.H. (2014) 'Citizen Engagement in Public Policy Making Process in Africa: The Case of Botswana', Public Policy and Administration Research, 3(4), pp. 1-11.

Okoh, R. (2007) 'Conflict Management in the Niger Delta region of Nigeria: a participatory approach', African Journal on Conflict Resolution, 5(1), pp. 91-114.

Orubu, C.O. et al. (2004) 'The Nigerian oil industry: environmental diseconomies, management 
strategies and the need for community involvement', Journal of Human Ecology, 16(3), pp. 203214.

Pegg, S. and Zabbey, N. (2013) 'Oil and water: the Bodo spills and the destruction of traditional livelihood structures in the Niger Delta', Community Development Journal, 48(3), pp. 391-405. Available at: 10.1093/cdj/bst021 (Accessed: 16 November 2015).

Péry, a. R.R. et al. (2013) 'Perspectives for integrating human and environmental risk assessment and synergies with socio-economic analysis', Science of the Total Environment, 456-457 Elsevier B.V., pp. 307-316.

Pollard, S.J.T. et al. (2004) 'Integrating decision tools for the sustainable management of land contamination', Science of the Total Environment, 325(1) Elsevier, pp. 15-28.

Prpich, G. et al. (2015) 'Review of the scientific evidence to support environmental risk assessment of shale gas development in the UK', Science of The Total Environment, Elsevier B.V.

Ramirez-Andreotta, M.D. et al. (2014) 'Environmental Research Translation: Enhancing interactions with communities at contaminated sites', Science of The Total Environment, 497-498, pp. 651-664.

Reed, M.S. (2008) 'Stakeholder participation for environmental management: A literature review', Biological Conservation, 141(10), pp. 2417-2431.

Rim-rukeh, A. (2015) 'Oil Spill Management in Nigeria: SWOT Analysis of the Joint Investigation Visit (JIV) Process', Journal of Environmental Protection, 6(March), pp. 259-271.

Rosén, L. et al. (2015) 'SCORE: A novel multi-criteria decision analysis approach to assessing the sustainability of contaminated land remediation', Science of The Total Environment, 511(0) Elsevier B.V., pp. 621-638.

Ross, P.S. and Birnbaum, L.S. (2003) 'Integrated Human and Ecological Risk Assessment: A Case Study of Persistent Organic Pollutants (POPs) in Humans and Wildlife', Human and Ecological Risk Assessment: An International Journal, 9(1), pp. 303-324.

Rowe, G. and Frewer, L.J. (2005) 'A Typology of Public Engagement Mechanisms', Science Technology and Human Values, 30(2), pp. 251-290.

Sam, K. et al. (2015) 'Environmental and Societal Management of contaminated land in Nigeria: the need for policy and guidance changes', 4th International Contaminated Site Remediation Conference: Program and Proceedings. Melbourne, Australia, pp. 427-428.

Sardinha, I.D. et al. (2013) 'A sustainability framework for redevelopment of rural brownfields: Stakeholder participation at SAO DOMINGOS mine, Portugal', Journal of Cleaner Production, 57 Elsevier Ltd, pp. 200-208.

Sekizawa, J. et al. (2003) 'Integrated Human and Ecological Risk Assessment: A Case Study of Tributyltin and Triphenyltin Compounds', Human and Ecological Risk Assessment, 9(1), pp. 325342.

Simon, E. et al. (2016) 'Understanding the fate of polycyclic aromatic hydrocarbons at a forest fire site using a conceptual model based on field monitoring', Journal of Hazardous Materials, 317 Elsevier B.V., pp. 632-639.

Smith, B.G. and Gallicano, T. (2015) 'Terms of engagement: Analyzing public engagement with organizations through social media', Computers in Human Behavior, 53 Elsevier Ltd, pp. 82-90.

Sojinu, O.S.S. et al. (2010) 'Polycyclic aromatic hydrocarbons in sediments and soils from oil exploration areas of the Niger Delta, Nigeria.', Journal of hazardous materials, 174(1-3), pp. 641-7. 
Stupak, N. (2016) 'Impact of Agricultural Transition on Soil Protection in Ukraine: The Role of Institutional Change', Land Use Policy, 55 Elsevier Ltd, pp. 86-97.

SuRF-UK (2010) A Framework for Assessing the Sustainability of Soil and Groundwater Remediation. London: CLAIRE.

Suter, G.W. et al. (2003) 'Types of integration in risk assessment and management, and why they are needed', Human and Ecological Risk Assessment, 9(1), pp. 273-279.

Suter, G.W. et al. (2005) 'An integrated framework for health and ecological risk assessment.', Toxicology and applied pharmacology, 207, pp. 611-6.

Swartjes, F.A. et al. (2012) 'State of the art of contaminated site management in The Netherlands: Policy framework and risk assessment tools', Science of the Total Environment, 427-428 Elsevier B.V., pp. 1-10.

The Guardian (2015) Oil spill - Shell announces £55m pay-out for Nigeria oil spills.

Thomsen, N.I. et al. (2016) 'A Bayesian belief network approach for assessing uncertainty in conceptual site models at contaminated sites', Journal of Contaminant Hydrology, 188 Elsevier B.V., pp. 12-28.

Umukoro, N. (2012) 'Governance and environmental inequality in Nigeria: Implications for conflict management strategies in the Niger Delta', International Journal of Environmental Studies, 69(6), pp. 913-920.

UNEP (2011) Environmental Assessment of Ogoniland. Switzerland: UNEP. Available at: http:/www.unep.org/disastersandconflicts/CountryOperations/Nigeria/EnvironmentalAssessmentof Ogonilandreport/tabid/54419/Default.aspx (Accessed: 15 February 2016).

Vegter, J. et al. (2002) Sustainable management of contaminated land: an overview. Austria: CLARINET.

Vermeire, T. et al. (2003) 'Integrated Human and Ecological Risk Assessment: A Case Study of Organophosphorous Pesticides in the Environment', Human and Ecological Risk Assessment, 9(1), pp. 343-357.

Vermeire, T. et al. (2007) 'An Assessment of Integrated Risk Assessment', Human and Ecological Risk Assessment: An International Journal, 13(January 2015), pp. 339-354.

Wilks, M.F. et al. (2015) 'White paper on the promotion of an integrated risk assessment concept in European regulatory frameworks for chemicals', Science of the Total Environment, 521522 Elsevier B.V., pp. 211-218.

Yeeles, A. and Akporiaye, A. (2016) 'Risk and resilience in the Nigerian oil sector: The economic effects of pipeline sabotage and theft', Energy Policy, 88 Elsevier, pp. 187-196. 